\title{
INTEGRATING SUSTAINABILITY INTO SUPPLIER SELECTION: A GREY-BASED TOPSIS ANALYSIS
}

\author{
Chunguang BAI ${ }^{1 *}$, Joseph SARKIS ${ }^{2}$ \\ ${ }^{1}$ School of Management and Economics, University of Electronic Science and Technology of China, \\ No. 2006, Xiyuan Ave, West Hi-Tech Zone, 611731, Chengdu, P. R. China \\ ${ }^{2}$ School of Business, Worcester Polytechnic Institute, 100 Institute Road, \\ Worcester, MA 01609-2280, USA
}

Received 25 August 2016; accepted 20 May 2018

\begin{abstract}
Sustainable supplier selection plays an important role in sustainable supply chain management operations and implementation. In this paper a novel formal modeling approach is conceptually developed and presented to address sustainable supplier selection. Grey theory and TOPSIS, a distance based multiple criteria method, are used for the integration and evaluation of sustainable supplier performance for sustainable supplier selection. From a research perspective, TOPSIS is improved to more effectively deal with grey numbers by integrating a degree of likelihood rather than converting grey numbers into crisp numbers functions, and it provides more flexible supplier rankings. This methodology strengthens the sustainable supplier selection process, and can be applied to other multiple criteria decision making problems. Illustrative calculations are made using data on sustainable supplier selection and evaluation published by Bai and Sarkis (2010). The technique is relatively accurate, matching well with results from a published grey rough set approach. The methodology easily implementable with minimal complex calculations required. It can also provide support for sustainable supplier selection, benchmarking, and improvement decisions. This is one of the first papers to integrate a broad set of sustainability factors for grey-based TOPSIS and supplier selection.
\end{abstract}

Keywords: supply chain management, multiple criteria evaluation, supplier selection, performance evaluation, grey set theory, TOPSIS.

JEL Classification: C02, D70, L25, O14.

\section{Introduction}

Effective corporate sustainability management does not occur only within the confines of an individual organization. The need for and consideration of supplier influence and the supply chain on product and process sustainability has become a truism (Wilhelm, Blome, Bhakoo, \& Paulraj, 2016; Mani, Gunasekaran, \& Delgado, 2018; Bai \& Sarkis, 2018a). To achieve

${ }^{\star}$ Corresponding author. E-mail: chunguang.bai@gmail.com

This is an Open Access article distributed under the terms of the Creative Commons Attribution License (http://creativecommons. org/licenses/by/4.0/), which permits unrestricted use, distribution, and reproduction in any medium, provided the original author and source are credited. 
true sustainable performance, consideration of supplier activities and characteristics, identifying the best sustainable fit with these suppliers, and then selecting them; are all critical and acknowledged steps by practitioners and researchers (Bai \& Sarkis, 2010; A. Kumar, Jain, \& S. Kumar, 2014a; Shahryari Nia, Olfat, Esmaeili, Rostamzadeh, \& Antuchevičienè, 2016).

The supplier selection literature is well established within the supply chain management field (Chai, Liu, \& Ngai, 2013). This area is one of the most popular formal modeling application within supply chain management (Awasthi \& Kannan, 2016; Rezaei, Nispeling, Sarkis, \& Tavasszy, 2016). Yet, explicit consideration of multiple performance dimensions, especially sustainability performance dimensions, is starting to receive attention amongst modelers and researchers (Genovese, Lenny Koh, Bruno, \& Esposito, 2013; Awasthi, Govindan, \& Gold, 2018). The selection and evaluation of suppliers goes hand-in-hand. Traditional approaches of only selecting the low-cost supplier are no longer a way for organizations to develop strategic competitive advantages. Factors for consideration have expanded from the single-dimension focused price orientation, to include quality, delivery, and flexibility (Bai \& Sarkis, 2018b). As the relationships between buyers and their suppliers become strategic the investigation of supplier and vendor selection has increased greatly.

Given that many of these supplier selection models can be applied to supplier performance, monitoring, and development purposes, their utility becomes even more pronounced. Incorporating sustainability, its triple-bottom-line and intergenerational long-term - 'super' strategic perspectives, although providing application usefulness, adds more complexity to the supplier selection and performance evaluation literature. For example, sustainable supplier selection decisions not only evaluate business and cost based performance, but also consider environmental and social sustainability performance. In addition, more authors are addressing supplier selection issues in the light of social and sustainability aspects; that are more broadly defined as sustainable supplier selection approaches (Kumar, Palaniappan, Kannan, \& Shankar, 2014b; Sarkis \& Dhavale, 2015; Fallahpour, Olugu, Musa, Wong, \& Noori, 2017). There still exists need for greater study of sustainable supplier management and selection issues (Kannan, Govindan, \& Rajendran, 2015; Ahmadi, Petrudi, \& Wang, 2017; Luthra, Govindan, Kannan, Mangla, \& Garg, 2017).

We provide a useful and powerful tool, based on simple logical measurement relationships to a close ideal and distant from a nadir (worst) performance evaluation. The approach is called the Technique for Order Preference by Similarity to Ideal Solution (TOPSIS), and its integration with grey-based approaches, provides an easily implementable approach that can be quickly utilized by management for sustainable supplier selection (Junior, Osiro, \& Carpinetti, 2014). The technique can be implemented on a simple spreadsheet, which can be used to monitor and select suppliers as the requirements evolve. The relative flexibility of the TOPSIS approach along with the unique and novel linkage of grey system theory, and degree of likelihood calculations, is a contribution of this research study to the literature. Its application to an existing data set allows for a comparative analysis and grounding the tool's validity.

The objective of this paper is to develop and apply the above mentioned technique to a sustainable supplier selection process. This research makes two major contributions. First, a novel likelihood multiple criteria decision making (MCDM) method that integrates TOPSIS and interval grey numbers, resulting in a likelihood value, is introduced. Under many suppli- 
er selection decisions, crisp data is insufficient to estimate vague decision maker evaluations. Grey numbers can incorporate vagueness of decision maker opinion and evaluation. Based on grey numbers, we introduce a new likelihood value for sustainable supplier ranking, which provides a more flexible supplier ranking. This approach provides a more accurate description and better ordering between two grey numbers. Thus, this grey hybrid likelihood MCDM model can strengthen the comprehensiveness of the vague decision making process, and can be successfully applied to various uncertain MCDM problems.

Secondly, the method and the sustainability supplier selection attributes system are applied to an illustrative case from Bai and Sarkis (2010) to aid supply chain managers evaluate sustainable suppliers. Simultaneously, we complete a comparative analysis and sensitivity analysis to demonstrate the proposed method's robustness and practicability. We also seek to provide some additional developmental and application directions for the research and practitioner community.

Thus, in this paper, we first provide some background on modeling for supplier selection and sustainable supplier selection. The modeling approach and technique is placed within the extant literature described in section 2. This discussion describes how this study contributes to this body of knowledge. We then provide an overview of grey systems theory, identifying its interval-type numbering system and mathematical operations. TOPSIS is then introduced, with the integration of grey numbers and grey mathematical operations. Using previously published data for sustainable supplier performance evaluation (Bai \& Sarkis, 2010), we then apply the grey-TOPSIS model and evaluate the results using a new degree of likelihood. A comparative analysis with a published grey-based Rough Set approach (Bai \& Sarkis, 2010) helps to validate and contrast this approach's strength and weaknesses.

\section{Traditional supplier and sustainable supplier selection and evaluation modeling}

Identifying suppliers of materials and products has become more important with greater outsourcing of processes and activities by modern organizations. Thus, supplier performance evaluation and supplier selection has taken on more strategic importance in companies. We discuss some of the needs in this area from the perspective of performance evaluation and supplier selection from both a traditional and sustainable supplier evaluation and selection process. Various tools for evaluation and supplier selection are overviewed to provide a foundation for the research presented in this study.

\subsection{Traditional supplier and sustainable supplier selection}

Supplier selection has evolved over the years from a commodity-based, operational decision to one that involves developing strategic decisions and relationships (Chai et al., 2013; Fallahpour, Amindoust, Antuchevičienè, \& Yazdani, 2017; Chatterjee \& Samarjit, 2018). Managing the supplier qualification and selection process is a necessary step for companies introducing supply chain management. Economic and cost based supplier selection is no longer acceptable for organizations that seek to introduce sustainability supply chain management issues. 
The sustainable supplier selection decision is a fundamental and important organizational sustainability management and decision. It mainly consists of two parts that must be considered in the decision-making process: a sustainable performance attributes system and decision support method.

First, sustainable supplier selection decisions require a performance system of attributes (criteria) that not only emphasize economic and cost based attributes, but also consider environmental and social sustainability factors. Some authors are addressing supplier selection issues in the light of green, ecological and environmental aspects, defined as green supplier selection (Kannan et al., 2015), environmental supplier selection (Shahryari Nia et al., 2016), or ecological supplier selection (Mahdiloo, Saen, \& Lee, 2015). In addition, more authors are addressing supplier selection issues in the light of social and sustainability aspects; that are more broadly defined as sustainable supplier selection approaches (Kumar et al., 2014b; Sarkis \& Dhavale, 2015). There still exists need for greater study of sustainable supplier management and selection issues (Kannan et al., 2015).

\subsection{Sustainable supplier evaluation modeling}

Due to the many and varied types of factors that are considered for supplier selection and evaluation, the use of multiple criteria decision models are the most prevalent formal modeling tools. A recent literature review from the first decade of this millennia showed that there were about 78 articles in peer reviewed journals that utilized some form of multiple criteria decision model for traditional supplier selection and evaluation approaches ( $\mathrm{Ho}, \mathrm{Xu}, \&$ Dey, 2010).

The most popular approaches have included formal modeling, multiple criteria tools such as data envelopment analysis (DEA), the analytical hierarchy and analytical network process (AHP/ANP respectively), mathematical programming, case-based reasoning (CBR), fuzzy set theory, genetic algorithms (GA), simple multi-attribute rating technique (SMART), and their hybrids (Ho et al., 2010). But, since that time more novel approaches have been included such as TOPSIS (Junior et al., 2014), rough set theory (entropy methods) (Bai \& Sarkis, 2012), and their hybrids (Shahryari Nia et al., 2016; Bai, Dhavale, \& Sarkis, 2016).

In the review of multiple criteria tools, very few papers (only 3 out of 78 ) considered environmental and/or safety factors in supplier selection (Ho et al., 2010). Broad-based sustainability considerations for supplier selection were not found in this literature. In a more recent review of the green supplier selection literature (Genovese et al., 2013), over a longer period of time and a broader scope of journals and tools, 28 articles relating to green supplier selection and evaluation were found. Most of these articles were quantitative based models and were recent to the literature. In addition to the approaches found in the general supplier selection literature, one technique using fuzzy-TOPSIS was found (Awasthi, Chauhan, \& Goyal, 2010). This paper (Awasthi et al., 2010) focused only on environmental factors and used a more specific fuzzy, rather than grey approach. A validation comparing TOPSIS to other techniques did not exist in the reviewed research.

Grey TOPSIS, similar to other techniques, has its advantages and disadvantages. Advantages include its relative mathematical transparency and ease-of-use. It can also be very effective in integrating a broad variety of factors including strategic, operational, tangible and 
intangible factors. Unlike tools such as AHP that require significant involvement from decision makers, historical or secondary data can be integrated into grey TOPSIS with little or no decision maker involvement. Although, in our case we do involve decision maker input.

Disadvantages include the need to identify and develop translational ranges using grey theory. The involvement can be pretty significant if all the data is required to be input from decision makers. Another disadvantage is when decision makers are involved, aggregation of decision maker inputs can occur through numerous ways from simple averaging to variations in weighted averages (of course this flexibility may be an advantage). If decision makers are integrated into the TOPSIS approach, the relative comparison of the many factors and suppliers becomes a difficult exercise, unlike the pairwise and hierarchical relationships that AHP and ANP provide.

Acknowledging these limitations and advantages is necessary for effective application. This paper will be the first that simultaneously considers a broader set of sustainability measures for supplier selection, integrating grey-approaches with TOPSIS, introducing a degree of likelihood measure, and seeking to further validate the approach using published data.

We now introduce grey system theory and the TOPSIS approach.

\section{Grey numbers and TOPSIS}

In this section we provide an overview and background of the two tools used in the multiple criteria, multiple decision maker sustainable supplier evaluation and selection approach. We begin with grey system theory (numbers), which sets the valuation approach we will use for intangible measures and metrics. TOPSIS is the second methodology reviewed in this section.

\subsection{Grey numbers}

Grey numbers and systems (Deng, 1989), can be used for systems with discrete data and incomplete information that have uncertainties. Grey numbers and systems can utilize relatively small data sets with great factor variability. It has been applied to supply chain management, economics, agriculture, medicine, geography, and disaster management (Bai \& Sarkis, 2017; Bai \& Sarkis, 2013). This grey numbering system is integrated with TOPSIS in this paper.

Definition 1: A grey number, $\otimes x$, can be expressed by an interval value $[\underline{x}, \bar{x}]$ with given upper and lower bounds but unknown distribution information for $x$ (Deng, 1989), where $\underline{x}$ and $\bar{x}$ are the lower and upper bounds of $\otimes x$, respectively. Then $\otimes x=[\underline{x}, \bar{x}]=\left[x^{\prime} \in x \mid \underline{x} \leq x^{\prime} \leq \bar{x}\right]$.

Definition 2: Let $\otimes x=[\underline{x}, \bar{x}]$ and $\otimes y=[y, \bar{y}]$ be two grey numbers. Mathematical operations of the interval grey number are defined as (expressions 1-4):

$$
\begin{aligned}
& \otimes x+\otimes y=[\underline{x}+\underline{y}, \bar{x}+\bar{y}] \\
& \otimes x-\otimes y=[\underline{x}-\bar{y}, \bar{x}-\underline{y}] ; \\
& \otimes x \times \otimes y=[\min (\underline{x} \underline{y}, \underline{x \bar{y}}, \bar{x} y, \overline{x y}), \max (\underline{x} \underline{y}, \underline{x \bar{y}}, \bar{x} \underline{y}, \overline{x y})] \\
& \otimes x \div \otimes y=[\underline{x}, \bar{x}] \times\left[\frac{1}{y}, \frac{1}{\bar{y}}\right] .
\end{aligned}
$$


Definition 3: Let $\otimes x=[\underline{x}, \bar{x}]$ and $\otimes y=[y, \bar{y}]$ be two interval grey numbers, with $l(\otimes x)=\bar{x}-\underline{x}$, and $l(\otimes y)=\bar{y}-y$. The larger degree of two interval grey numbers has previously been defined. We now define the larger degrees for a interval grey numbers as:

$$
P(\otimes x \geq \otimes y)= \begin{cases}1 & \underline{x} \geq \bar{y} \\ \frac{\bar{x}-y}{l(\otimes x)+l(\otimes y)} & \bar{x}>\underline{y} \wedge \underline{x}<\bar{y}, \\ 0 & \bar{x} \leq \underline{y}\end{cases}
$$

where $P(\otimes x \geq \otimes y)>50 \%$ means that the interval grey number $\otimes x$ is larger than interval grey number $\otimes y$. These relationships will be utilized to advance the TOPSIS method.

\subsection{The TOPSIS method}

The TOPSIS is a multiple criteria decision methodology. TOPSIS evaluates alternatives by determining a shortest distance from the ideal (best) solution and the largest distance from the nadir (poorest) solution (Junior et al., 2014). The TOPSIS methodology includes:

1) Decision matrix $U=\left(x_{i j}\right)_{n \times m}$ normalizations. In our model, we develop some grey scale matrix (see Tables 3 and 5) to map all data types over the same grey system range of " $0-1$ ".

2) Determine the ideal and nadir solutions.

$$
\begin{aligned}
& S^{+}=\left\{v_{1}^{+}, \ldots, v_{m}^{+}\right\}=\left\{\left(\max _{i} v_{i j} \mid j \in I\right),\left(\min _{i} v_{i j} \mid j \in J\right)\right\} ; \\
& S^{-}=\left\{v_{1}^{-}, \ldots, v_{m}^{-}\right\}=\left\{\left(\min _{i} v_{i j} \mid j \in I\right),\left(\max _{i} v_{i j} \mid j \in J\right)\right\},
\end{aligned}
$$

where $I$ represents criteria that improve as they get larger, and $J$ represents criteria that improve as they get smaller.

3) Distance measures using the $n$-dimensional Euclidian space distance for the ideal solution are calculated using:

$$
\mu_{i}^{+}=\sqrt{\sum_{j=1}^{m}\left(v_{i j}-v_{j}^{+}\right)^{2}}, i=1, \ldots, n .
$$

For the nadir solution distance the calculation is:

$$
\mu_{i}^{-}=\sqrt{\sum_{j=1}^{m}\left(v_{i j}-v_{j}^{-}\right)^{2}}, i=1, \ldots, n .
$$

4) A closeness metric $T$ is then determined using

$$
T_{i}=\frac{\mu_{i}^{-}}{\mu_{i}^{+}+\mu_{i}^{-}} .
$$

5) The final preference order ranking is by ordering in decreasing values.

Details of the technique using the grey numbering system are now presented in an illustrative problem. 


\section{A case illustration and sensitivity analysis}

The illustrative case, using the values of Bai and Sarkis (2010), provide us with insights into application of grey number and TOPSIS approaches for selection of supplier based on sustainability attributes. The proposed technique is composed of 9 steps, which are summarized in Figure 1. Each of these steps is presented in detail with the operations explicitly identified. The first 6 steps in this methodology are from Bai and Sarkis (2010), but repeated in this paper for the purpose of completeness and clarity and to prepare the illustrative grey data for application of the grey based TOPSIS approach and comparative analysis. In section 4.2 we will then complete a sensitivity analysis that provides a variety of solutions depending on the factors used in the analysis.

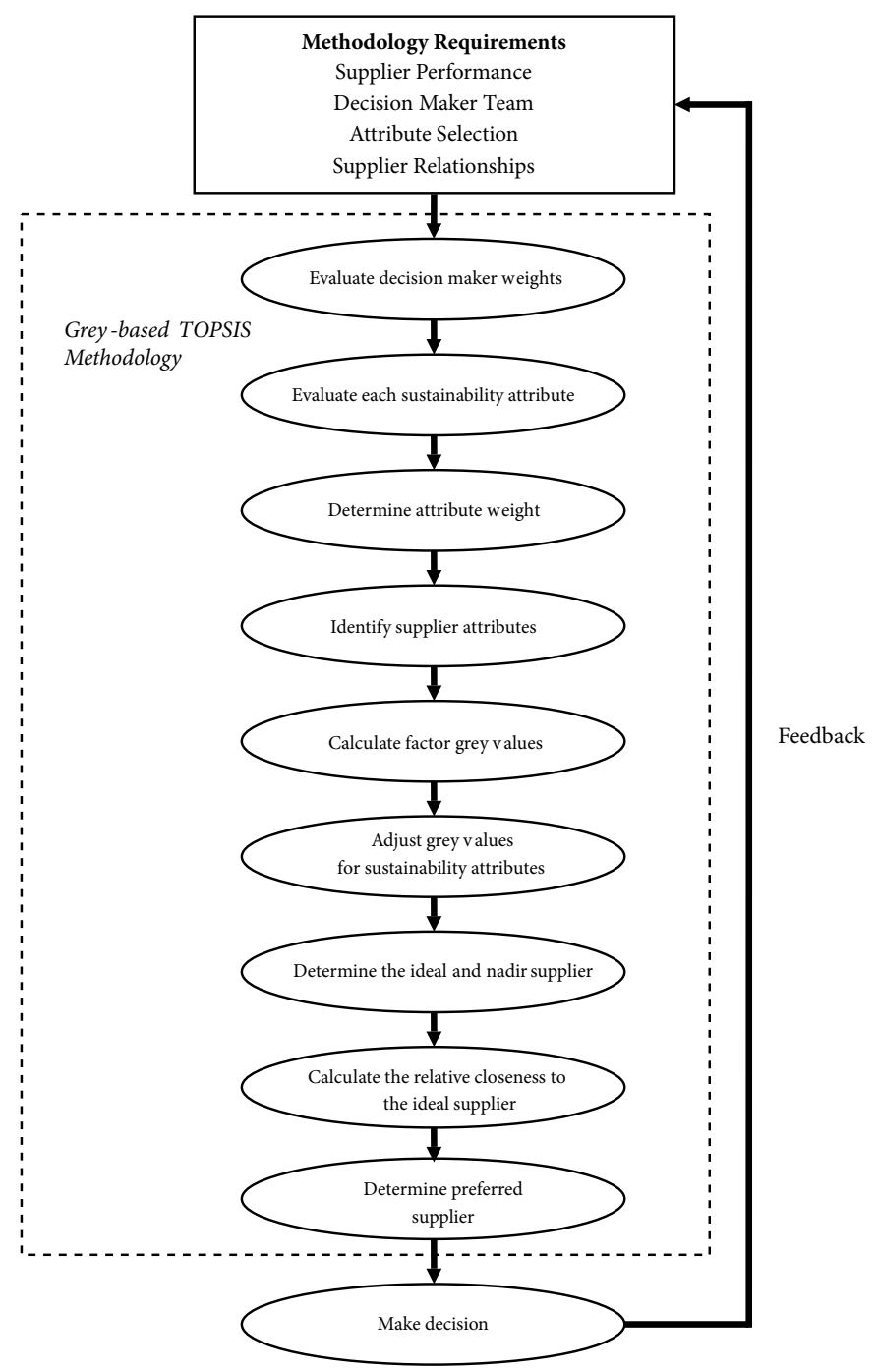

Figure 1. Various steps and environment of the joint Grey number and TOPSIS methodology 


\subsection{The grey-based TOPSIS methodology applied to the case data}

First, in this subsection, for further elicitation of the grey based TOPSIS we shall introduce notation and development of the Grey decision table for supplier selection. First, let us assume that a database of suppliers exists (a Grey table). This table is defined by $T=(U, A, V)$, where $U=\left\{S_{1}, S_{2}, \ldots S_{\mathrm{n}}\right\}$ is a set of $n$ alternative suppliers called the universe. $A=\left\{a_{1}, a_{2}, \ldots, a_{\mathrm{m}}\right\}$ is a set of $m$ attributes for the suppliers.

For our illustrative case $U=\left\{S_{i}, i=1,2, \cdots, 30\right\}$ (i.e. thirty suppliers) with nine attributes $A=\left\{a_{j}, j=1,2,3, \cdots 9\right\}$ each. The attributes represent the three triple-bottom-line factors for sustainability. We will assume three factors for each of the triple bottom items. We have three environmental attributes, Ev1, Ev2, and Ev3; three economic/business attributes Ec1, Ec2, and Ec3; and three social attributes So1, So2, and So3. These three attributes may be distilled by the analysts from the numerous factors identified in Table 1.

Table 1. Sustainability supplier selection attributes

\begin{tabular}{|c|c|c|}
\hline Triple-bottom-line Factors & Categories & Factors \\
\hline \multirow{8}{*}{$\begin{array}{l}\text { Business and Economic } \\
\text { metrics } \\
\text { (Based on Sarkis \& Talluri, } \\
2002 \text { and Chan, 2003) }\end{array}$} & \multirow{5}{*}{$\begin{array}{l}\text { Strategic Performance } \\
\text { Measures }\end{array}$} & Cost \\
\hline & & Quality \\
\hline & & Time \\
\hline & & Flexibility \\
\hline & & Innovativeness \\
\hline & \multirow{3}{*}{ Organizational Factors } & Culture \\
\hline & & Technology \\
\hline & & Relationship \\
\hline \multirow{5}{*}{$\begin{array}{l}\text { Environmental metrics } \\
\text { (Source: Gauthier, 2005) }\end{array}$} & \multirow{3}{*}{ Environmental Practices } & Pollution Controls \\
\hline & & Pollution Prevention \\
\hline & & Environmental Management System \\
\hline & \multirow{2}{*}{ Environmental Performance } & Resource Consumption \\
\hline & & Pollution Production \\
\hline \multirow{5}{*}{$\begin{array}{l}\text { Social metrics } \\
\text { (Sources: Gauthier, 2005; } \\
\text { Labuschagne, Brent, \& } \\
\text { Claasen, 2005) }\end{array}$} & \multirow{2}{*}{ Internal Social Criteria } & Employment Practices \\
\hline & & Health and Safety \\
\hline & \multirow{3}{*}{ External Social Criteria } & Local Communities Influence \\
\hline & & Contractual Stakeholders Influence \\
\hline & & Other Stakeholders Influence \\
\hline
\end{tabular}

In the case illustration, using data, which published by Bai and Sarkis (2010), on sustainable supplier selection and evaluation, we also same assume there are 4 decision makers, an Operations Manager (DM1), a Financial Manager (DM2). These are the same four types of managers assumed in Bai and Sarkis (2010). The 9 step procedure and details to arrive at our final selection and/or ranking of sustainable suppliers is now shown. 
Step 1: Evaluate and assign the importance level for each decision maker

The importance of each decision maker and their input into the decision is defined by the grey scale variable vector $\otimes d^{k}=\left[\underline{d}^{k}, \bar{d}^{k}\right]$. For the four decision makers with $(k \in K$ and $K=1, \ldots, 4)$, the following grey scale importance levels exist: $\otimes d^{1}=\left[d^{1}, \bar{d}^{-1}\right]=[0.7,0.9]$ (decision maker $D 1$ is at the 'Important' level), $\otimes d^{2}=[0.5,0.7]$ ('Moderately Important' level for decision maker $D 2), \otimes d^{3}=[0.9,1.0]$ ('Very Important' level for decision maker D3), $\otimes d^{4}=$ $[0.5,0.7]$ ( 'Moderately Important' level for decision maker D4).

\section{Step 2: Acquire the relative importance of each sustainability attribute from} each decision maker and assign scale values

Each decision maker $k$ evaluates each sustainability factor $j$. The team members assign textual perceptual scores ranging from very low to very high for each attribute. See Table 2.

Table 2. Grey scale variable matrix for initial evaluations of sustainability factor importance by each decision maker

\begin{tabular}{|c|c|c|c|c|c|c|c|c|c|}
\hline \multirow{2}{*}{$\begin{array}{c}\text { Decision } \\
\text { Maker }\end{array}$} & \multicolumn{3}{|c|}{ Environmental Factors } & \multicolumn{2}{c|}{ Economic/Business Factors } & \multicolumn{3}{|c|}{ Social Factors } \\
\cline { 2 - 11 } & Ev1 & Ev2 & Ev3 & Ec1 & Ec2 & Ec3 & So1 & So2 & So3 \\
\hline D1 & $\mathrm{M}$ & $\mathrm{M}$ & $\mathrm{M}$ & $\mathrm{VH}$ & $\mathrm{H}$ & $\mathrm{VH}$ & $\mathrm{VH}$ & $\mathrm{M}$ & $\mathrm{M}$ \\
\hline $\mathrm{D} 2$ & $\mathrm{M}$ & $\mathrm{SH}$ & $\mathrm{M}$ & $\mathrm{VH}$ & $\mathrm{VH}$ & $\mathrm{VH}$ & $\mathrm{SH}$ & $\mathrm{SH}$ & $\mathrm{H}$ \\
\hline $\mathrm{D} 3$ & $\mathrm{H}$ & $\mathrm{M}$ & $\mathrm{H}$ & $\mathrm{H}$ & $\mathrm{H}$ & $\mathrm{H}$ & $\mathrm{H}$ & $\mathrm{H}$ & $\mathrm{H}$ \\
\hline $\mathrm{D} 4$ & $\mathrm{VH}$ & $\mathrm{VH}$ & $\mathrm{VH}$ & $\mathrm{H}$ & $\mathrm{H}$ & $\mathrm{M}$ & $\mathrm{VH}$ & $\mathrm{H}$ & $\mathrm{VH}$ \\
\hline
\end{tabular}

These evaluations result in the grey scale variable matrix $\otimes w=\otimes w_{j}^{k}=\left[\underline{w}_{j}^{k}, \bar{w}_{j}^{k}\right], j=1 \ldots m$. The seven level grey scales for the evaluation of sustainability factors importance are shown in Table 3.

Table 3. The scale of attribute level of importance $\otimes w$

\begin{tabular}{|l|c|}
\hline \multicolumn{1}{|c|}{ Scale } & $\otimes w$ \\
\hline Very Low $(\mathrm{VL})$ & {$[0,0.1]$} \\
\hline Low $(\mathrm{L})$ & {$[0.1,0.3]$} \\
\hline Somewhat Moderate (SM) & {$[0.3,0.4]$} \\
\hline Moderate (M) & {$[0.4,0.6]$} \\
\hline Somewhat High (SH) & {$[0.6,0.7]$} \\
\hline High $(\mathrm{H})$ & {$[0.7,0.9]$} \\
\hline Very High $(\mathrm{VH})$ & {$[0.9,1.0]$} \\
\hline
\end{tabular}

From Tables 2 and 3 grey scale importance values $\otimes w_{j}^{k}$ for each sustainability factor $j$ and decision maker $k$ are determined. As an example, for Ev1 (i.e. $j=1$ ) and across all decision makers $(k=1, \ldots, 4))$ the factor grey scale importance values are assumed to be $\otimes w_{1}^{1}=$ $[0.4,0.6], \otimes w_{1}^{2}=[0.4,0.6], \otimes w_{1}^{3}=[0.7,0.9], \otimes w_{1}^{4}=[0.9,1.0]$. 


\section{Step 3: Adjust final attribute weight level $\otimes \tilde{w}_{j}$ using decision maker information}

We first determine the adjusted attribute importance weight for each attribute $j$ and decision maker $k\left(\otimes \tilde{w}_{j}^{k}\right)$. We do this with expression (11):

$$
\otimes \tilde{w}_{j}^{k}=\otimes w_{j}^{k} \times \otimes d^{k}=\left[\min \left(\underline{w}_{j}^{k} \underline{d}^{k}, \underline{w}_{j}^{k} \bar{d}^{k}, \bar{w}_{j}^{k} \underline{d}^{k}, \bar{w}_{j}^{k} \bar{d}^{k}\right), \max \left(\underline{w}_{j}^{k} \underline{d}^{k}, \underline{w}_{j}^{k} \bar{d}^{k}, \bar{w}_{j}^{k} \underline{d}^{k}, \bar{w}_{j}^{k} \bar{d} k\right)\right] .
$$

For example, the adjusted attribute importance weight for $\operatorname{Ev1}(j=1)$ and decision maker $1(k=1)$ is $\otimes \tilde{w}_{1}^{1}=\otimes w_{1}^{1} \times \otimes d_{1}^{1}=[\min (0.7 \times 0.4,0.7 \times 0.6,0.9 \times 0.4,0.9 \times 0.6), \max (0.7 \times 0.4,0.7 \times 0.6$, $0.9 \times 0.4,0.9 \times 0.6)]=[0.28,0.54]$. Notice that in this case all that was required was the use of $\underline{w}_{j}^{k} \underline{d}^{k}$ for the lowest value and $\bar{w}_{j} \bar{d}^{k}$ for the highest value of the grey scale. In general, if negative values are included, the more general equation (11) is needed. The average variable importance weight for the decision makers is determined using expression (12).

$$
\otimes \tilde{w}_{j}=\frac{1}{K}\left[\otimes \tilde{w}_{j}^{1}+\otimes \tilde{w}_{j}^{2}+\cdots+\otimes \tilde{w}_{j}^{K}\right] .
$$

The final adjusted attribute importance weight grey scale values are shown in Table 4.

\section{Step 4: Determine performance levels of suppliers on various sustainability factors}

From the team of decision-makers the attribute values of suppliers on each of the sustainability attributes will be determined. The team members assign textual perceptual scores ranging from very poor to very good for each supplier and their attributes. The seven level scale used in this study is shown in Table 5. A grey scale score $\otimes v$ will be assigned to each supplier $(i)$ by each decision maker $(k)$ for each attribute $(j)$ for each respective scale level.

The textual assignments for the case example are shown in Table 6. Decision makers would need to evaluate the 30 suppliers, on each of the nine sustainability attributes.

Table 4 . The adjusted attribute importance values $\otimes \tilde{w}_{j}$

\begin{tabular}{|c|c|}
\hline $\begin{array}{c}\text { Sustainability } \\
\text { Factor }\end{array}$ & $\begin{array}{c}\text { Average Adjusted Importance } \\
\text { Weight }\left(\otimes \tilde{w}_{j}\right)\end{array}$ \\
\hline Ev1 & {$[0.39,0.64]$} \\
\hline Ev2 & {$[0.35,0.58]$} \\
\hline Ev3 & {$[0.39,0.64]$} \\
\hline Ec1 & {$[0.52,0.78]$} \\
\hline Ec2 & {$[0.48,0.76]$} \\
\hline Ec3 & {$[0.48,0.73]$} \\
\hline So1 & {$[0.50,0.75]$} \\
\hline So2 & {$[0.39,0.64]$} \\
\hline So3 & {$[0.43,0.69]$} \\
\hline
\end{tabular}

Table 5. The scale of attribute ratings $\otimes v$

\begin{tabular}{|l|c|}
\hline \multicolumn{1}{|c|}{ Scale } & $\otimes v$ \\
\hline Very poor (VP) & {$[0,0.1]$} \\
\hline Poor (P) & {$[0.1,0.3]$} \\
\hline Somewhat Fair (SF) & {$[0.3,0.4]$} \\
\hline Fair (F) & {$[0.4,0.5]$} \\
\hline Somewhat Good (SG) & {$[0.5,0.6]$} \\
\hline Good (G) & {$[0.6,0.9]$} \\
\hline Very Good (VG) & {$[0.9,1.0]$} \\
\hline
\end{tabular}




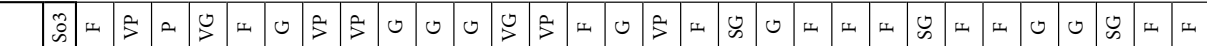
递山 ○

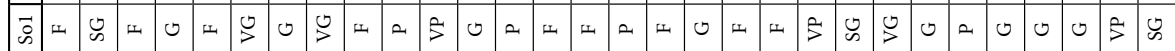

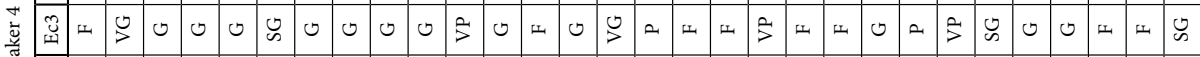
䔰 壱署 总山

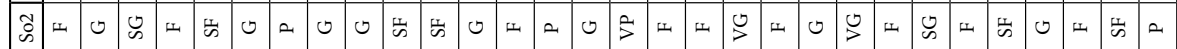

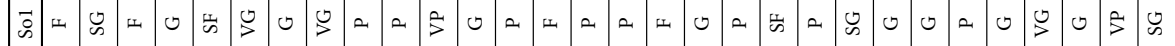
密

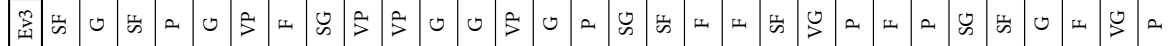

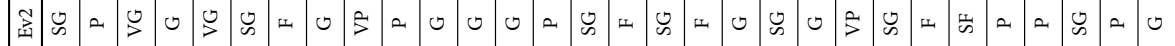
壱穷 总崖

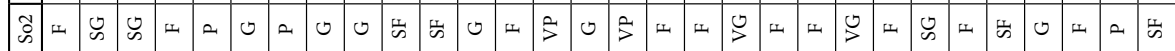

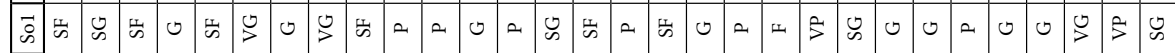
竞

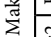

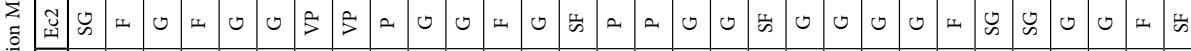
密

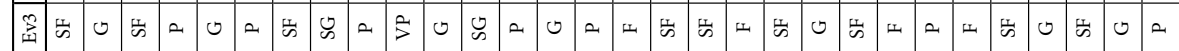
䍃 壱 总炭 总希

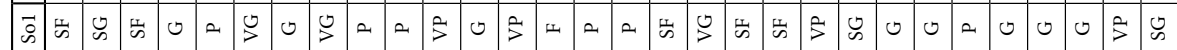

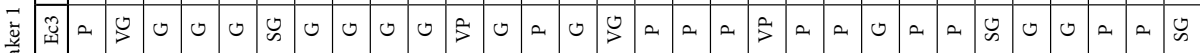
聯

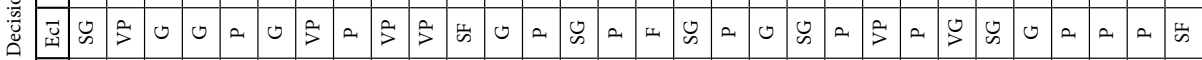

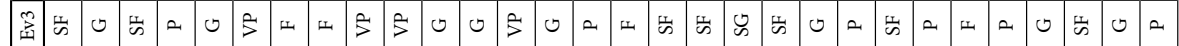

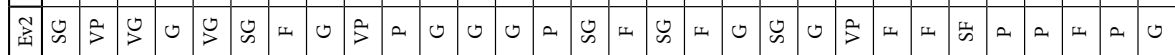
嫍 


\section{Step 5: Calculate unadjusted aggregated grey values performance levels of suppliers for each sustainability attribute}

In this step a single unadjusted evaluation of the aggregate (across the decision team) grey values for each of the major sustainability factors is determined. Assuming that a decision team has $K$ persons, then the aggregated grey values for supplier $i$ factor $j, \otimes v_{i j}$, can be calculated as:

$$
\otimes v_{i j}=\frac{1}{K} \sum_{k=1}^{K} \otimes v_{i j}^{k} \times \otimes d^{k}, \forall i, j,
$$

where $\otimes v_{i j}^{k}(i=1,2, \cdots n ; j=1,2, \cdots m ; k=1,2, \cdots K)$ is the attribute rating value of the $k^{\text {th }}$ decision maker for supplier $i$, attribute $j$ and can be described by grey number $\otimes v_{i j}^{k}=\left[\underline{v}_{i j}^{k}, \bar{v}_{i j}^{k}\right]$.

As an example calculation, the grey value for supplier 1 , factor $1\left(\otimes v_{11}\right)$ is:

$$
\begin{aligned}
& \otimes v_{11}=\frac{1}{4}\left[0.7^{\star} 0.6+0.5^{\star} 0.9+0.9{ }^{\star} 0.9+0.5^{\star} 0.9\right), \\
& \left.\left.0.99^{\star} 0.9+0.7^{\star} 1.0+1.0^{\star} 1.0+0.7^{\star} 1.0\right)\right]=[0.533,0.803] .
\end{aligned}
$$

\begin{tabular}{|c|c|c|c|c|c|c|c|c|c|}
\hline & & & & & & & & So2 & 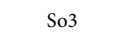 \\
\hline & & & & & & & & & \\
\hline & & & & & & & & & \\
\hline & & & & & & & & & \\
\hline & 585 & 3] & .065 & 3] & 35] & 43] & 3] & 3] & \\
\hline & & & 3] & 18] & & ] & & & \\
\hline & & & & & & & & & \\
\hline & & & & & & & & & \\
\hline & & 37 & 30 & 12 & {$[0.05$} & {$[0.39$} & {$[0.58$} & 0.3 & \\
\hline Supt & ] & ,0.083] & {$[0.013$} & 0.035 & {$[0.06$} & 43] & {$[0.12$} & 3] & {$[0.39$} \\
\hline 10 & & 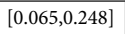 & & & & {$[0.03$} & 8] & 3] & {$[0.3$} \\
\hline & & & & & & & & & \\
\hline & & & & & & & & & \\
\hline 13 & ] & 43] & ] & 053 & {$[0.39$,} & 3] & 3] & 35] & \\
\hline 14 & 00 & 8] & {$[0.39$} & 7] & {$[0.2$} & .42 & & {$[0.0$} & {$[0.12$} \\
\hline 15 & {$[0.26$,} & ] & 065 & 06 & 3] & .58 & {$[0.12$} & {$[0.35$} & {$[0.3$} \\
\hline & (n) & ats & ale & (2) & {$[0.06$} & 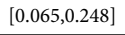 & {$[0.06$} & & \\
\hline 117 & & +5 & $\mathrm{c}^{-1}$ & 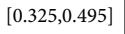 & & ] & & {$[0.243,0$} & {$[0.22$} \\
\hline 18 & {$[0$} & [0 & 2 & 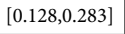 & $x^{2}+2>$ & 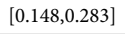 & {$[0.4$} & {$[0.278$} & {$[0.33$} \\
\hline r 19 & {$[0.26, \mathrm{C}$} & .428 & {$[0.278$} & {$[0.368,0$.} & {$[0.163$} & {$[0,0$} & {$[0.138$} & {$[0.58$} & {$[0.3 \mathrm{~s}$} \\
\hline 20 & 53 & & 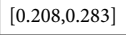 & 32 & 8] & .173 & {$[0.2$} & {$[0.24$} & {$[0.2$} \\
\hline & 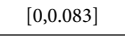 & . & {$[0.495$} & {$[0.045$,} & {$[0.39$,} & 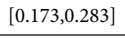 & {$[0.023$} & {$[0.530$,} & {$[0.2$} \\
\hline er 22 & . & & - & {$[0.013$} & & {$[0.39$,} & 5] & {$[0$} & {$[0$.} \\
\hline 23 & {$[0.39$,} & 283 & {$[0.23$} & . & 10. & 3] & & & 2 \\
\hline 24 & {$[0.013$,} & 3] & {$[0.065$} & .585 & {$[0.278$} & {$[0.018$} & {$[0.39$} & {$[0.32$} & {$[0.22$} \\
\hline 25 & 1000 & 208, & {$[0.283$} & {$[0.303$} & {$[0.36$} & {$[0.36$, } & {$[0.06$} & {$[0.26$, } & {$[0.248$,} \\
\hline 26 & {$[0.005$} & 005 & {$[0.173$} & {$[0.533$} & {$[0.2$} & {$[0.368$} & {$[0.35$} & {$[0.208$} & {$[0.39,0$} \\
\hline 27 & {$[0.043,0.19$} & $\pi$ & {$[0.39$,} & {$[0.12$} & {$[0.39,0.743]$} & 3] & {$[0.458$} & $50-20$ & ] \\
\hline Su & {$[0$} & {$[0.283,0.438]$} & {$[0.23,0.333]$} & {$[0.128,0.283]$} & {$[0.39,0.743]$} & ] & $-5+3$ & & {$[0.338,0.548]$} \\
\hline 29 & {$[0$.} & 8] & {$[0$.} & {$[0.053,0.213]$} & 3] & {$[0.148,0.283]$} & & ] & {$[0.2$} \\
\hline Supplier 30 & $.175,0.318]$ & {$[0.39,0.743]$} & {$[0.065,0.248]$} & {$[0.208,0.283]$} & {$[0.09,0.248]$} & {$[0.303,0.47]$} & {$[0.325,0.495]$} & {$[0.128,0.283]$} & {$[0.26,0.413]$} \\
\hline
\end{tabular}

Raw (non-adjusted) total grey factor supplier scores are summarized in Table 7.

Table 7. Unadjusted aggregate grey scores of suppliers on sustainability factors $\left(\otimes v_{i j}\right)$ 


\section{Step 6: Determine adjusted aggregated grey values performance levels of suppliers for each sustainability attribute}

In this step we seek to adjust the aggregated factor weight scores determined in step 5 by adjusting these scores for each supplier $i\left(\otimes v_{i j}\right)$ with adjusted attribute $j$ importance weighting $\left(\otimes \tilde{w}_{j}\right)$.

The adjusted total factor weight scores $\otimes \tilde{v}_{i j}$ are calculated using (14):

$\otimes \tilde{v}_{i j}=\otimes \tilde{w}_{j} \times \otimes v_{i j}=\left[\min \left(\underline{\tilde{w}}_{j} \underline{v}_{i j}, \underline{\tilde{w}}_{j} \bar{v}_{i j}, \overline{\tilde{w}}_{j} \underline{v}_{i j}, \overline{\tilde{w}}_{j} \bar{v}_{i j}\right), \max \left(\underline{\tilde{w}}_{j} \underline{v}_{i j}, \underline{\tilde{w}}_{j} \bar{v}_{i j}, \overline{\tilde{w}}_{j} \underline{v}_{i j}, \overline{\tilde{w}}_{j} \bar{v}_{i j}\right)\right] \quad \forall i \in n$.

For supplier 1's first environmental factor, the adjusted grey value is: $\otimes \tilde{v}_{11}=\otimes \tilde{w}_{1} \times \otimes v_{11}=$ $[\min (0.39 \times 0.533,0.39 \times 0.803,0.64 \times 0.533,0.64 \times 0.803), \max (0.39 \times 0.533,0.39 \times 0.803,0.64 \times 0.53$, $0.64 \times 0.803)]=[0.208,0.514]$.

A summary of the adjusted aggregate grey factor scores results appear in Table 8.

Table 8. Adjusted grey scores of suppliers on sustainability factors $\left(\otimes \tilde{v}_{i j}\right)$

\begin{tabular}{|c|c|c|c|c|c|c|c|c|c|}
\hline & & 2 & 3 & & 22 & 3 & 01 & 2 & 3 \\
\hline & & & & & & & & & \\
\hline & & & & & & & & & \\
\hline & & & & & & & & 7] & {$[0.028$} \\
\hline 11 & & $137,0.431]$ & ] & ] & & 2] & 7] & 4] & {$[0.229,0.554]$} \\
\hline & & & & 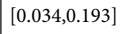 & & & 2] & & 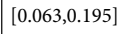 \\
\hline St & & & ] & ] & & 1] & 9] & 5] & {$[0.168$,} \\
\hline & & 9] & $.097,0.242]$ & & 1] & 2] & 7] & 6] & {$[0$.} \\
\hline Supp & 1] & 4] & {$[0.1$} & ] & 2] & {$[0.18$} & 619] & {$[0.15$} & \\
\hline $\mathrm{Su}$ & & $8]$ & ] & ] & & ] & 2] & ] & 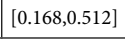 \\
\hline$S_{u}$ & ] & 144] & & & & ] & 6] & 1] & {$[0.168,0.512]$} \\
\hline Su & & & & & & & & & \\
\hline & & & & & & & & & \\
\hline & & & & 6] & & & & & \\
\hline $\mathrm{Su}$ & & & 5] & 5] & & {$[0.2$} & 3] & {$[0.00$} & {$[0.05$} \\
\hline Supp & 4] & 7] & 8] & {$[0$} & 2] & {$[0.2$} & {$[0.0$} & {$[0.1$} & {$[0.1$} \\
\hline Supp & 3] & $.091,0.239]$ & {$[0.11,0.28]$} & 5] & 8] & {$[0.03$} & ] & {$[0,0.053]$} & {$[0,0.057]$} \\
\hline St & & 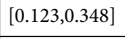 & 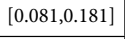 & [ & & [c & & 5] & [ \\
\hline & & & & & & & & & \\
\hline Suppli & & $0.15,0.441]$ & & [ & & & & & {$[0.168,0.51$} \\
\hline Sup & 4] & & ] ] & & & & & & \\
\hline Supp & & $1]$ & {$[0.19$} & {$[0.02$} & & {$[0.0$} & {$[0.0$} & {$[0.1$} & {$[0.1$} \\
\hline Supp & 4] & $0048]$ & 8] & {$[0$} & 4] & {$[0$.} & {$[0.1$} & {$[0.2$} & {$[0$.} \\
\hline $\mathrm{Su}$ & ] & {$[0.099,0.254]$} & {$[0.09,0.213]$} & {$[0.066,0.22]$} & 4] & {$[0$} & ] & 5] & {$[0$.} \\
\hline & & & & & & & & & \\
\hline Supplier 25 & & {$[0.073,0.164]$} & & ] & {$[0.173,0.473]$} & [c & 6] & 4] & {$[0.106,0.26]$} \\
\hline $\mathrm{Su}$ & ] & 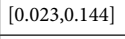 & ] & 6] & 7] & {$[0$} & 7] & $1]$ & [0. \\
\hline Supp & 6] & 4] & {$[0.15$} & {$[0.6$} & 4] & {$[0$.} & {$[0.2$} & {$[0.1$} & {$[0.1$} \\
\hline Suppl & & & [ & & 4] & {$[0 . c$} & & 8] & {$[0.145$} \\
\hline $\mathrm{Su}$ & ] & ] & ] & {$[0$} & 3] & {$[0$} & {$[0,0.06$} & 1] & {$[0.089,0.195]$} \\
\hline Supplier 30 & ] & $.137,0.431]$ & {$[0.025,0.158]$} & {$[0.108,0.22]$} & {$[0.043,0.188]$} & 3] & 1] & 1] & {$[0.112,0.285]$} \\
\hline & $.528,0.528]$ & (7) & 1 & {$[0.644,0.644]$} & $50-54054]$ & {$[0.602,0.602]$} & {$[0.619,0.619]$} & {$[0.528,0.528]$} & \\
\hline Nadir Supplier & $.000,0.000]$ & $0.000,0.000]$ & $.000,0.000]$ & $0.000,0.000]$ & {$[0.011,0.011]$} & {$[0.000,0.000]$} & {$[0.000,0.000]$} & {$[0.000,0.000]$} & $10.000,0.00$ \\
\hline
\end{tabular}




\section{Step 7: Determine the grey ideal and nadir suppliers}

Given that grey valuations already have been normalized, we do not require an additional step to normalize the decision matrix. In this example all factors are beneficial measures (the bigger the value the better) and we can now determine the ideal and nadir solutions.

Initially the most 'ideal' reference supplier $S^{+}(\otimes \tilde{v})$ is determined by using the maximum factor value in the set or:

$$
S^{+}=\left\{\otimes \tilde{v}_{j}^{+}\right\}=\left\{\underline{\tilde{v}}_{j}^{+}, \overline{\tilde{v}}_{j}^{+}\right\}=\left\{\left(\max _{i} \overline{\tilde{v}}_{i j}, \max _{i} \overline{\tilde{v}}_{i j}\right)\right\}, j=1, \ldots, m .
$$

Using this approach, the most 'ideal' reference sustainability supplier alternative $S^{+}$and its values is:

$$
\begin{aligned}
& S^{+}=\{[0.528,0.528],[0.479,0.479],[0.502,0.502],[0.644,0.644],[0.564,0.564],[0.602,0.602], \\
& [0.619,0.619],[0.528,0.528],[0.569,0.569]\} .
\end{aligned}
$$

The most grey 'nadir' reference supplier $S^{-}(\otimes \tilde{v})$ is composed of the minimum value from each factor which is:

$$
S^{-}=\left\{\otimes \tilde{v}_{j}^{-}\right\}=\left\{\underline{\tilde{v}}_{j}^{-}, \overline{\tilde{v}}_{j}^{-}\right\}=\left\{\left(\min _{i} \underline{\tilde{v}}_{i j}, \min _{i} \underline{\tilde{v}}_{i j}\right)\right\}, j=1, \ldots, m .
$$

Thus, the most grey 'nadir' reference sustainability supplier alternative $S^{-}$is determined as:

$S^{-}=\{[0.000,0.000],[0.000,0.000],[0.000,0.000],[0.000,0.000],[0.011,0.011],[0.000$, $0.000],[0.000,0.000],[0.000,0.000],[0.000,0.000]\}$.

\section{Step 8: Calculate the distance for grey separation measure}

Based on the TOPSIS separation measure expressions (8) and (9), a new grey separation measure for an object and 'ideal' (expression 17) and 'nadir' (expression 18) alternative for a given decision factor are determined.

$$
\begin{aligned}
& \otimes \mu_{i}^{+}\left(S^{+}, S_{i}\right)=\sum_{j=1}^{m}\left(\otimes \tilde{v}_{j}^{+}-\otimes \tilde{v}_{i j}\right)=\sum_{j=1}^{m}\left(\left(\underline{\tilde{v}}_{j}^{+}-\bar{v}_{i j}\right),\left(\overline{\tilde{v}}_{k}^{+}-\underline{v}_{i j}\right)\right) ; \\
& \otimes \mu_{i}^{-}\left(S^{-}, S_{i}\right)=\sum_{j=1}^{m}\left(\otimes \tilde{v}_{i j}-\otimes \tilde{v}_{j}^{-}\right)=\sum_{j=1}^{m}\left[\left(\underline{v}_{i j}-\overline{\tilde{v}}_{j}^{-}\right),\left(\bar{v}_{i j}-\underline{v}_{j}^{-}\right)\right] .
\end{aligned}
$$

For the illustrative example, for the calculation of $\otimes \mu_{1}^{+}$from expression (17) is:

$$
\begin{aligned}
& \otimes \mu_{1}^{+}=\sum_{j=1}^{m}\left(\otimes \tilde{v}_{j}^{+}-\otimes \tilde{v}_{i j}\right)= \\
& {[(0.528-0.514),(0.528-0.208)]+\sum_{j=2}^{m}\left(\otimes \tilde{v}_{j}^{+}-\otimes \tilde{v}_{i j}\right)=} \\
& {[0.0144,0.320]+\sum_{j=2}^{m}\left(\otimes \tilde{v}_{j}^{+}-\otimes \tilde{v}_{i j}\right)=[2.253,3.897] .}
\end{aligned}
$$

The suppliers grey separation distances from the ideal point are shown in Table 9. 
Table 9. The relative closeness of suppliers and ranking

\begin{tabular}{|l|c|c|c|c|}
\hline & $\mu_{i}^{+}$ & $\mu_{i}^{-}$ & $T_{i}$ & Ranking \\
\hline Supplier 1 & {$[2.253,3.897]$} & {$[1.127,2.771]$} & {$[0.169,0.416]$} & 13 \\
\hline Supplier 2 & {$[2.47,4.078]$} & {$[0.946,2.554]$} & {$[0.143,0.385]$} & 20 \\
\hline Supplier 3 & {$[1.451,3.709]$} & {$[1.315,3.573]$} & {$[0.181,0.491]$} & 4 \\
\hline Supplier 4 & {$[1.092,3.596]$} & {$[1.428,3.933]$} & {$[0.19,0.522]$} & 3 \\
\hline Supplier 5 & {$[1.701,3.878]$} & {$[1.146,3.323]$} & {$[0.159,0.461]$} & 6 \\
\hline Supplier 6 & {$[1.182,3.555]$} & {$[1.469,3.842]$} & {$[0.199,0.519]$} & 2 \\
\hline Supplier 7 & {$[2.767,4.307]$} & {$[0.717,2.257]$} & {$[0.109,0.344]$} & 26 \\
\hline Supplier 8 & {$[2.077,4.002]$} & {$[1.022,2.947]$} & {$[0.147,0.424]$} & 16 \\
\hline Supplier 9 & {$[2.693,4.385]$} & {$[0.64,2.331]$} & {$[0.095,0.347]$} & 27 \\
\hline Supplier 10 & {$[2.314,4.218]$} & {$[0.806,2.71]$} & {$[0.116,0.391]$} & 23 \\
\hline Supplier 11 & {$[2.516,4.22]$} & {$[0.804,2.508]$} & {$[0.12,0.373]$} & 24 \\
\hline Supplier 12 & {$[\mathbf{0 . 6 3 4 , 3 . 4 7 7}]$} & {$[\mathbf{1 . 5 4 7 , 4 . 3 9}]$} & {$[\mathbf{0 . 1 9 7 , 0 . 5 5 8}]$} & $\mathbf{1}$ \\
\hline Supplier 13 & {$[2.947,4.451]$} & {$[0.573,2.077]$} & {$[0.088,0.318]$} & 29 \\
\hline Supplier 14 & {$[2.441,4.149]$} & {$[0.875,2.583]$} & {$[0.13,0.384]$} & 22 \\
\hline Supplier 15 & {$[2.205,4.076]$} & {$[0.948,2.819]$} & {$[0.137,0.409]$} & 18 \\
\hline Supplier 16 & {$[3.338,4.56]$} & {$[0.464,1.686]$} & {$[0.074,0.27]$} & 30 \\
\hline Supplier 17 & {$[2.28,3.906]$} & {$[1.118,2.744]$} & {$[0.168,0.413]$} & 14 \\
\hline Supplier 18 & {$[1.877,3.899]$} & {$[1.125,3.147]$} & {$[0.16,0.447]$} & 8 \\
\hline Supplier 19 & {$[2.004,3.942]$} & {$[1.082,3.02]$} & {$[0.155,0.434]$} & 12 \\
\hline Supplier 20 & {$[2.292,3.911]$} & {$[1.113,2.732]$} & {$[0.168,0.411]$} & 15 \\
\hline Supplier 21 & {$[2.387,4.16]$} & {$[0.865,2.637]$} & {$[0.127,0.388]$} & 21 \\
\hline Supplier 22 & {$[2.202,4.027]$} & {$[0.997,2.822]$} & {$[0.146,0.412]$} & 17 \\
\hline Supplier 23 & {$[1.879,3.905]$} & {$[1.119,3.145]$} & {$[0.159,0.446]$} & 9 \\
\hline Supplier 24 & {$[2.395,4.049]$} & {$[0.975,2.629]$} & {$[0.146,0.394]$} & 19 \\
\hline Supplier 25 & {$[2.075,3.907]$} & {$[1.117,2.949]$} & {$[0.163,0.43]$} & 11 \\
\hline Supplier 26 & {$[1.862,3.892]$} & {$[1.132,3.162]$} & {$[0.161,0.448]$} & 7 \\
\hline Supplier 27 & {$[1.4,3.854]$} & {$[1.17,3.624]$} & {$[0.156,0.485]$} & 5 \\
\hline Supplier 28 & {$[1.876,3.903]$} & {$[1.121,3.148]$} & {$[0.159,0.446]$} & 9 \\
\hline Supplier 29 & {$[2.893,4.318]$} & {$[0.706,2.131]$} & {$[0.11,0.33]$} & 28 \\
\hline Supplier 30 & {$[2.654,4.185]$} & {$[0.84,2.37]$} & {$[0.128,0.362]$} & 25 \\
\hline
\end{tabular}

For the grey separation distance from the nadir point an example calculation for $\otimes \mu_{1}^{-}$ using expression (18) is now presented:

$$
\begin{aligned}
& \otimes \mu_{i}^{-}=\sum_{j=1}^{m}\left(\otimes \tilde{v}_{i j}-\otimes \tilde{v}_{j}^{-}\right)=[(0.208-0.000),(0.514-0.000)]+\sum_{j=2}^{m}\left(\otimes \tilde{v}_{i j}-\otimes \tilde{v}_{j}^{-}\right)= \\
& {[0.208,0.514]+\sum_{j=2}^{m}\left(\otimes \tilde{v}_{i j}-\otimes \tilde{v}_{j}^{-}\right)=[1.127,2.771] .}
\end{aligned}
$$

The final grey separation distances from the ideal point for each supplier are summarized in Table 9. 


\section{Step 9: The grey relative closeness value from the ideal solution is determined}

A grey relative distance measure $\otimes T_{i}$ for an alternative $S_{i}$ is calculated using:

$$
\otimes T_{i}=\frac{\otimes \mu_{i}^{-}}{\otimes \mu_{i}^{+}+\otimes \mu_{i}^{-}}=\frac{\left(\underline{\mu}_{i}^{-}, \bar{\mu}_{i}^{-}\right)}{\left(\underline{\mu}_{i}^{+}+\underline{\mu}_{i}^{-}, \bar{\mu}_{i}^{+}+\bar{\mu}_{i}^{-}\right)}=\left[\underline{\mu}_{i}^{-} /\left(\bar{\mu}_{i}^{+}+\bar{\mu}_{i}^{-}\right)^{\prime} \bar{\mu}_{i}^{-} /\left(\bar{\mu}_{i}^{+}+\bar{\mu}_{i}^{-}\right)\right] .
$$

The final comparative distances $\otimes T_{i}$ are summarized in Table 9. For Supplier 1 this value is determined as follows:

$$
\otimes T_{1}=\frac{\otimes \mu_{1}^{-}}{\otimes \mu_{1}^{+}+\otimes \mu_{1}^{-}}=\left[\frac{1.127}{2.771+3.897}, \frac{2.771}{2.771+3.897}\right]=[0.169,0.416] .
$$

The grey relative closeness values for each supplier are in the form of interval grey numbers, such as $[0.169,0.416]$ for Supplier 1 and $[0.143,0.385]$ for Supplier 2. It is difficult to directly judge whether Supplier 1 or Supplier 2 is better based on the grey relative closeness values. The traditional approach is to convert grey numbers into crisp numbers, but this conversion will cause some information loss, such as the breadth of the interval of numbers. To overcome this limitation, a degree of likelihood measure is introduced in the next step.

\section{Step 10: Rank the suppliers using degree of likelihood}

In this step, we will extend the TOPSIS evaluation using the degree of likelihood that one supplier is better than another supplier. The degree of likelihood comparison for any two suppliers is first determined by expression (5). Then, the degree of likelihood for each supplier can be initially determined by establishing a matrix using expression (20):

$$
P_{n \times n}=p\left(\otimes T_{i} \geq \otimes T_{h}\right)_{n \times n} i, h=1, \ldots, n .
$$

For the illustrative example, the grey relative closeness level $\otimes T_{1}=[0.169,0.416]$ of Supplier 01. The grey relative closeness level of Supplier 02 is $\otimes T_{2}=[0.143,0.385]$. This result shows that the degree of likelihood that Supplier 01 is bigger than Supplier 02 is $p\left(\otimes T_{1} \geq \otimes T_{2}\right)=\frac{\overline{T_{1}}-\underline{T_{2}}}{\overline{T_{1}}-\underline{T_{1}}+\overline{\overline{T_{2}}}-\underline{T_{2}}}=\frac{0.416-0.143}{0.247+0.242}=55.8 \%>50.0 \%$. This result means that Supplier 01 is $55.8 \%$ more likely to be better than Supplier 02 . The degree of likelihood that one alternative (supplier) is ranked higher than another is summarized in a matrix shown in Table 10.

The results in Table 10 show Supplier 12 is the most preferred supplier. The final ranks are: $S_{12}>S_{52.7 \%} S_{06} \underset{50.5 \%}{\succ} S_{04} \underset{52.6 \%}{\succ} S_{03} \underset{53.2 \%}{\succ} S_{27} \cdots$. The expression " $S_{12} \underset{52.7 \%}{>} S_{06}$ " means that Supplier 12 is more preferred than Supplier 06 based on the selected attributes and attribute valuations.

The larger degree of likelihood percentage helps for ordering all suppliers. $T_{i}$ value based on the larger degree represents a more superior alternative. Thus, with a score of [0.197, 0.558 ], sustainability alternative supplier 12 is the most preferred alternative from among the 30 alternatives in the original set. 


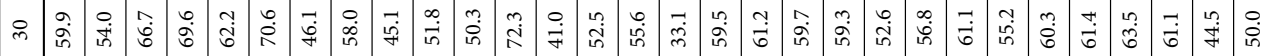

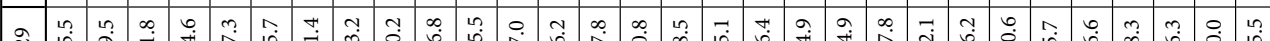

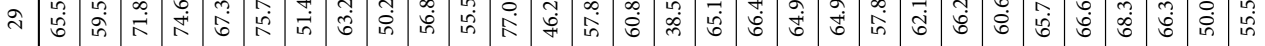

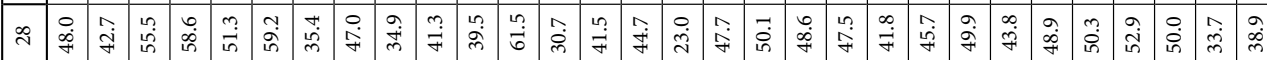

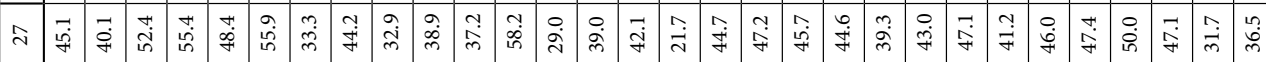

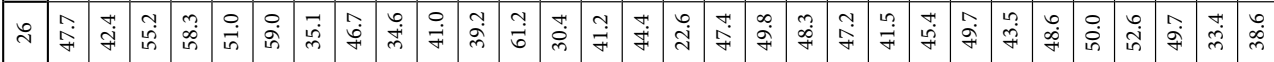

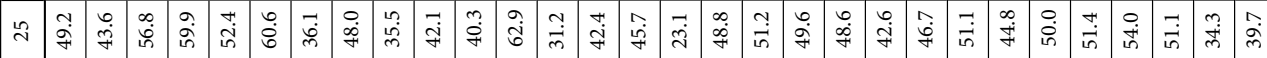

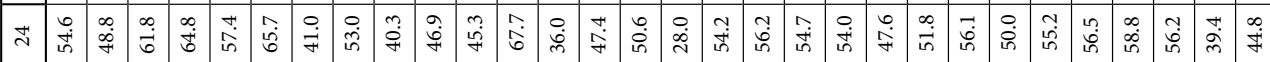

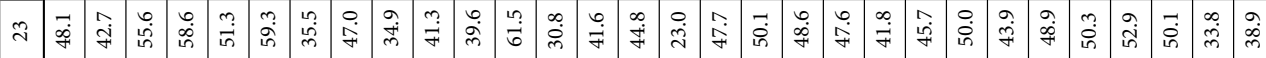
八

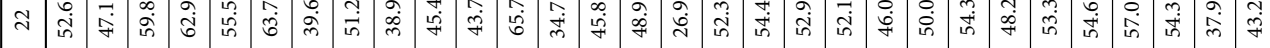

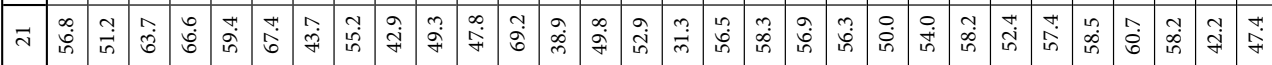

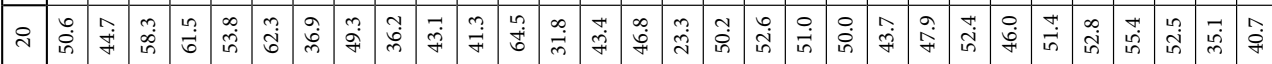

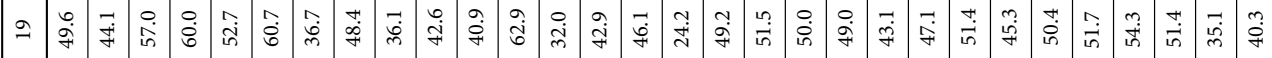

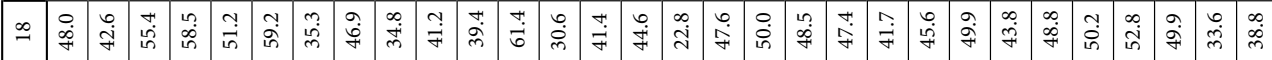

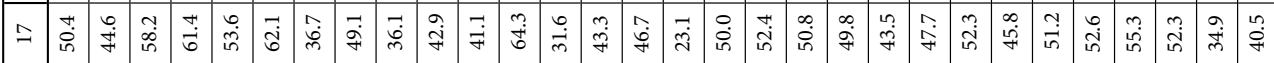

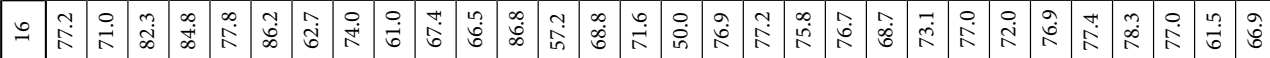

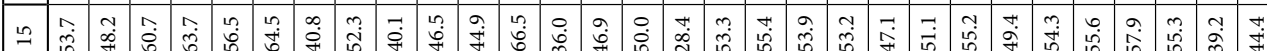

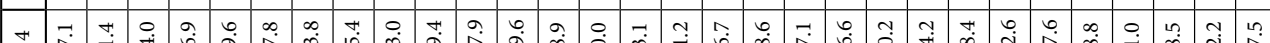

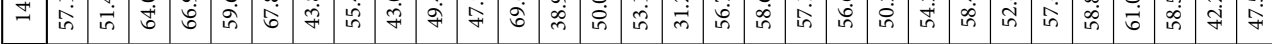

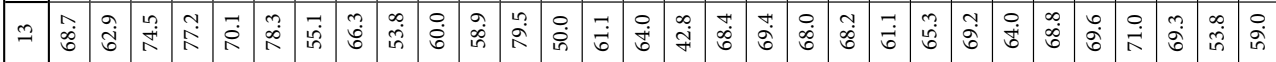

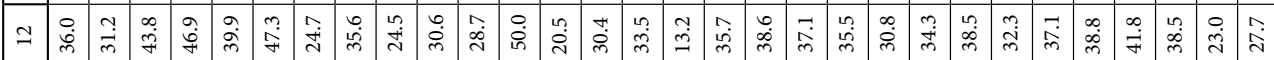

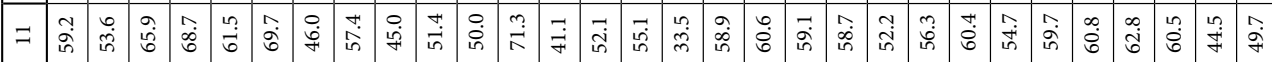

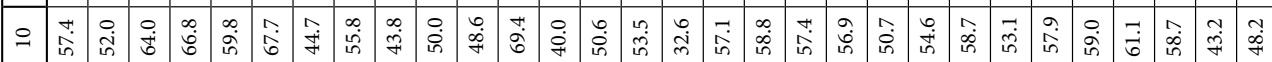

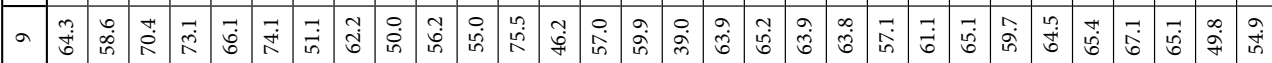

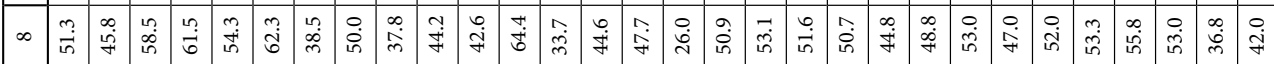

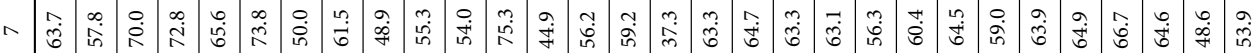

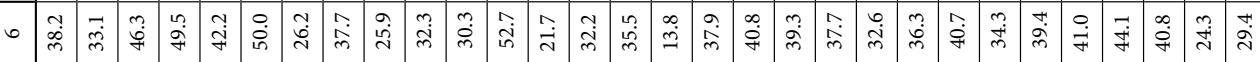

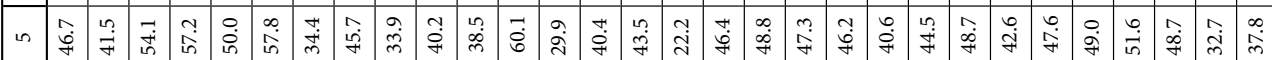

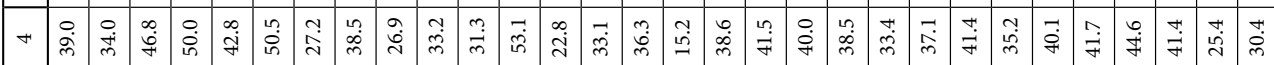

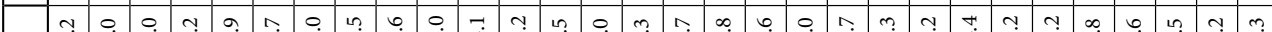
Zु 
Interestingly the top ranked supplier in this technique and the grey-based rough set approach identified by Bai and Sarkis (2010) were exactly the same, Supplier 12. This initial result shows that the grey-based TOPSIS technique, which is mathematically less complex and in many ways more intuitive than rough set theory, provides the exact same solution for the best supplier. In fact, the top six suppliers (these were the only ones ranked in the acceptable set in Bai and Sarkis (2010) were the same set and only two suppliers were transposed in the ranking comparison. Supplier 4 and Supplier 6 were ranked second and third best by the grey rough set approach of Bai and Sarkis (2010), while they were ranked third and second in this paper. But, overall, there was substantial consistency in the approaches.

But will it always be this way? Bai and Sarkis (2010) did not consider the importance level for each decision maker in the unadjusted aggregated grey value performance levels of suppliers (Step 5). Bai and Sarkis (2010) only used the importance level for each decision maker for determining the weight level of each attribute. That's not necessarily a reasonable approach. We now show that the importance level for each decision maker can be very influential in the evaluation process. This result shows that analysts and managers should be careful when determining decision maker importance levels.

\subsection{A sensitivity analysis}

For the sensitivity analysis three additional scenarios are introduced to determine the solution robustness. In this sensitivity analysis the three additional scenarios represent the solution when only a portion of the triple-bottom-line factors are considered for supplier selection and evaluation. The first scenario, see Table 11, uses economic/business attributes (Ec1, Ec2, and Ec3) only to help evaluate the suppliers. The second scenario considers only environmental attributes (Ev1, Ev2, and Ev3), while the third scenario considers only the social attributes (So1, So2, and So3) to evaluate the suppliers. Specifically, we will investigate what happens to our solution sets (and preferred supplier) when we choose a different set of attributes.

Supplier rankings do change in some of the scenarios. Supplier $\mathrm{S}_{3}$ becomes the preferred supplier when only economic or business attributes are considered (scenario 1). Bai and Sarkis (2010), who did consider economic factors as one of their scenarios found supplier $\mathrm{S}_{3}$ to be more preferred. For scenario 2, only environmental attributes are considered, supplier $\mathrm{S}_{5}$ ranks highest. The analysis of this situation is that this supplier does not pay attention to focusing on economic/business performance, especially not social performance. When only social attributes are considered the third scenario, supplier $\mathrm{S}_{6}$ becomes most preferred. Interestingly, supplier $\mathrm{S}_{12}$ was always second or third best supplier in all scenarios (not including the initial scenario). This result provides another idea of how well a supplier will perform overall.

These changes in most preferred supplier represents a major caveat in the application of this approach. That is, analysts and decision makers must be careful in determining which categories and factors to consider. The results also provide insights into possible TOPSIS tool misapplication where decisions using only partial criteria can provide inaccurate results. 
Table 11. Results of the sensitivity analysis

\begin{tabular}{|c|c|c|c|c|c|c|c|c|}
\hline Alternatives & $\begin{array}{c}\text { Initial } \\
\text { Scenario }\end{array}$ & Ranking & $\begin{array}{c}\text { Scenario } \\
1\end{array}$ & Ranking & $\begin{array}{c}\text { Scenario } \\
2\end{array}$ & Ranking & $\begin{array}{c}\text { Scenario } \\
3\end{array}$ & Ranking \\
\hline Supplier 1 & {$[0.169,0.416]$} & 13 & {$[0.169,0.422]$} & 12 & {$[0.192,0.487]$} & 4 & {$[0.145,0.337]$} & 18 \\
\hline Supplier 2 & {$[0.143,0.385]$} & 20 & {$[0.165,0.399]$} & 16 & {$[0.12,0.366]$} & 20 & {$[0.139,0.388]$} & 15 \\
\hline Supplier 3 & {$[0.181,0.491]$} & 4 & {$[0.195,0.576]$} & 1 & {$[0.218,0.53]$} & 2 & {$[0.124,0.338]$} & 21 \\
\hline Supplier 4 & {$[0.19,0.522]$} & 3 & {$[0.188,0.528]$} & 3 & {$[0.174,0.5]$} & 7 & {$[0.205,0.536]$} & 4 \\
\hline Supplier 5 & {$[0.159,0.461]$} & 6 & {$[0.161,0.488]$} & 9 & {$[0.21,0.588]$} & 1 & {$[0.099,0.28]$} & 26 \\
\hline Supplier 6 & {$[0.199,0.519]$} & 2 & {$[0.194,0.511]$} & 5 & {$[0.169,0.434]$} & 15 & {$[0.226,0.593]$} & 1 \\
\hline Supplier 7 & {$[0.109,0.344]$} & 26 & {$[0.081,0.302]$} & 30 & {$[0.156,0.396]$} & 18 & {$[0.097,0.341]$} & 24 \\
\hline Supplier 8 & {$[0.147,0.424]$} & 16 & {$[0.11,0.374]$} & 23 & {$[0.149,0.424]$} & 16 & {$[0.184,0.475]$} & 11 \\
\hline Supplier 9 & {$[0.095,0.347]$} & 27 & {$[0.093,0.351]$} & 27 & {$[0.017,0.16]$} & 30 & {$[0.151,0.474]$} & 13 \\
\hline Supplier 10 & {$[0.116,0.391]$} & 23 & {$[0.14,0.447]$} & 13 & {$[0.087,0.335]$} & 25 & {$[0.115,0.378]$} & 17 \\
\hline Supplier 11 & {$[0.12,0.373]$} & 24 & {$[0.121,0.346]$} & 24 & {$[0.132,0.44]$} & 17 & {$[0.106,0.335]$} & 23 \\
\hline Supplier 12 & {$[0.197,0.558]$} & 1 & {$[0.188,0.528]$} & 3 & {$[0.18,0.557]$} & 3 & {$[0.22,0.589]$} & 2 \\
\hline Supplier 13 & {$[0.088,0.318]$} & 29 & {$[0.112,0.378]$} & 22 & {$[0.083,0.331]$} & 26 & {$[0.064,0.235]$} & 28 \\
\hline Supplier 14 & {$[0.13,0.384]$} & 22 & {$[0.188,0.476]$} & 7 & {$[0.096,0.373]$} & 22 & {$[0.094,0.284]$} & 27 \\
\hline Supplier 15 & {$[0.137,0.409]$} & 18 & {$[0.136,0.392]$} & 17 & {$[0.122,0.359]$} & 21 & {$[0.151,0.465]$} & 14 \\
\hline Supplier 16 & {$[0.074,0.27]$} & 30 & {$[0.089,0.309]$} & 29 & {$[0.116,0.346]$} & 23 & {$[0.016,0.149]$} & 30 \\
\hline Supplier 17 & {$[0.168,0.413]$} & 14 & {$[0.168,0.417]$} & 14 & {$[0.192,0.487]$} & 4 & {$[0.144,0.333]$} & 19 \\
\hline Supplier 18 & {$[0.16,0.447]$} & 8 & {$[0.127,0.397]$} & 18 & {$[0.16,0.444]$} & 14 & {$[0.192,0.498]$} & 5 \\
\hline Supplier 19 & {$[0.155,0.434]$} & 12 & {$[0.111,0.337]$} & 26 & {$[0.168,0.461]$} & 9 & {$[0.186,0.5]$} & 6 \\
\hline Supplier 20 & {$[0.168,0.411]$} & 15 & {$[0.168,0.417]$} & 14 & {$[0.192,0.487]$} & 4 & {$[0.142,0.328]$} & 20 \\
\hline Supplier 21 & {$[0.127,0.388]$} & 21 & {$[0.116,0.376]$} & 21 & {$[0.152,0.455]$} & 11 & {$[0.115,0.335]$} & 22 \\
\hline Supplier 22 & {$[0.146,0.412]$} & 17 & {$[0.141,0.454]$} & 11 & {$[0.084,0.286]$} & 27 & {$[0.2,0.467]$} & 10 \\
\hline Supplier 23 & {$[0.159,0.446]$} & 9 & {$[0.127,0.397]$} & 18 & {$[0.161,0.446]$} & 11 & {$[0.188,0.494]$} & 8 \\
\hline Supplier 24 & {$[0.146,0.394]$} & 19 & {$[0.18,0.436]$} & 10 & {$[0.065,0.254]$} & 29 & {$[0.175,0.459]$} & 12 \\
\hline Supplier 25 & {$[0.163,0.43]$} & 11 & {$[0.19,0.495]$} & 6 & {$[0.185,0.46]$} & 8 & {$[0.11,0.325]$} & 25 \\
\hline Supplier 26 & {$[0.161,0.448]$} & 7 & {$[0.216,0.538]$} & 2 & {$[0.061,0.257]$} & 28 & {$[0.176,0.496]$} & 9 \\
\hline Supplier 27 & {$[0.156,0.485]$} & 5 & {$[0.16,0.49]$} & 8 & {$[0.093,0.361]$} & 24 & {$[0.201,0.572]$} & 3 \\
\hline Supplier 28 & {$[0.159,0.446]$} & 9 & {$[0.127,0.397]$} & 18 & {$[0.161,0.446]$} & 11 & {$[0.189,0.495]$} & 7 \\
\hline Supplier 29 & {$[0.11,0.33]$} & 28 & {$[0.098,0.306]$} & 28 & {$[0.155,0.46]$} & 10 & {$[0.073,0.218]$} & 29 \\
\hline Supplier 30 & {$[0.128,0.362]$} & 25 & {$[0.127,0.329]$} & 25 & {$[0.111,0.383]$} & 19 & {$[0.145,0.375]$} & 16 \\
\hline
\end{tabular}




\section{Conclusions and future scope of research}

In this paper, we introduced grey-based TOPSIS as a multi-stage (multiple computational steps), multi-method (integration of multiple methods such as grey number and TOPSIS), multi-metric (dealing with multidimensional sustainability attributes) method to evaluate and select suppliers using sustainability factors and a conceptual application. This technique is a useful approach for managers, and researchers, who seek to evaluate supplier performance in various studies. A single aggregate and relative performance metric is determined to evaluate the best supplier or provide a ranking of suppliers. The technique can be applied in a regular spreadsheet situation, can take into consideration a variety of metrics, both tangible and intangible, and can be applied with very little outside effort from decision makers and be based completely on archival data if necessary. Given that the real world and practical evaluations of suppliers can be subjective and objective, such a technique can prove valuable with the first application of TOPSIS with grey based numbering and likelihood degree.

We utilized published data from Bai and Sarkis (2010) to help validate the tool and provide insight into its operational execution, results and validity. Overall, we found the technique to provide relatively consistent results of top performing suppliers when compared with the more complex and less intuitively appealing grey-rough set theory approach. This result was most evident when the most comprehensive set of factors were considered. But the results are more sensitive and less likely to match with the rough set theoretic approach when only the economic/business attributes are considered. The reason may be that Bai and Sarkis (2010) have variations in the decision-making information integrating previous organizational knowledge and learning into the decision process.

In terms of practical application, this approach not only can choose the best supplier from amongst the candidates, but it can be used to identify suppliers that require improvement or identify the suppliers with which to terminate cooperation. That is the tool can be used for sustainable supplier benchmarking or a choice model to remove poorly performing suppliers.

From the sensitivity analysis the findings indicated that the final decision will be sensitive to the attributes that are used in the evaluation process. In this specific application, we also found that a preferred sustainability supplier should do well on performance in all economic/ business, environmental and social attributes.

Limitations of the proposed methodology also provide avenues for further research. One major limitation of the research presented in this paper is that the historical decisions are not effectively integrated into the evaluation model. That is, historical selection data on whether a supplier was previously selected or used by the organization is not effectively integrated with the basic TOPSIS approach. In this situation historical data variables may be integrated directly into the technique or a rough-set linkage considering various sets of previous selections could be integrated with the TOPISIS technique. Also, actual historical performance of the suppliers and the previous decisions related to these suppliers are critical information. Organizations can further refine their decision making quality to either maintain some consistency and/or improve their decision process with further weighting and development of attributes that are salient for the organization's strategic direction. This will require actual longitudinal data in which organizations can learn to improve their sustainability measures 
and selection of suppliers. Another issue is the concern with missing information and data that typically occurs in real world situations. TOPSIS approaches for incomplete and missing data do not exist. Extending TOPSIS to incorporate incomplete data is clearly a direction for future research and development. Last, some brainstorming and expert consensus data gather methods such as the DELPHI can be applied to arrive at decision matrix inputs from decision makers.

In summary, even with practical and methodological limitations and concerns, TOPSIS is a simple, evolving, and potentially powerful tool for decision makers and researchers, especially in complex decision environments associated with sustainability. We feel these formal models play an important role in improving supply chain management and supplier selection. Introducing a grey-TOPSIS contributes to building additional knowledge in sustainability, supply chain management, performance management, and multiple criteria decision making and evaluation. It also sets the foundation for significant lines of additional research.

\section{Acknowledgements}

This work is supported by the National Natural Science Foundation of China Project (71472031, 71772032).

\section{References}

Ahmadi, H. B., Petrudi, S. H. H., \& Wang, X. (2017). Integrating sustainability into supplier selection with analytical hierarchy process and improved grey relational analysis: a case of telecom industry. The International Journal of Advanced Manufacturing Technology, 90(9-12), 2413-2427. https://doi.org/10.1007/s00170-016-9518-Z

Awasthi, A., Chauhan, S. S., \& Goyal, S. (2010). A fuzzy multicriteria approach for evaluating environmental performance of suppliers. International Journal of Production Economics, 126(2), 370-378. https://doi.org/10.1016/j.ijpe.2010.04.029

Awasthi, A., Govindan, K., \& Gold, S. (2018). Multi-tier sustainable global supplier selection using a fuzzy AHP-VIKOR based approach. International Journal of Production Economics, 195, 106-117. https://doi.org/10.1016/j.ijpe.2017.10.013

Awasthi, A., \& Kannan, G. (2016). Green supplier development program selection using NGT and VIKOR under fuzzy environment. Computers \& Industrial Engineering, 91, 100-108. https://doi.org/10.1016/j.cie.2015.11.011

Bai, C., Dhavale, D., \& Sarkis, J. (2016). Complex investment decisions using rough set and fuzzy cmeans: an example of investment in green supply chains. European Journal of Operational Research, 248(2), 507-521. https://doi.org/10.1016/j.ejor.2015.07.059

Bai, C., \& Sarkis, J. (2010). Integrating sustainability into supplier selection with grey system and rough set methodologies. International Journal of Production Economics, 124(1), 252-264.

https://doi.org/10.1016/j.ijpe.2009.11.023

Bai, C., \& Sarkis, J. (2012). Supply-chain performance-measurement system management using neighbourhood rough sets. International Journal of Production Research, 50(9), 2484-2500. https://doi.org/10.1080/00207543.2011.581010

Bai, C., \& Sarkis, J. (2013). A grey-based DEMATEL model for evaluating business process management critical success factors. International Journal of Production Economics, 146(1), 281-292.

https://doi.org/10.1016/j.ijpe.2013.07.011 
Bai, C., \& Sarkis, J. (2017). Improving green flexibility through advanced manufacturing technology investment: modeling the decision process. International Journal of Production Economics, 188, 86104. https://doi.org/10.1016/j.ijpe.2017.03.013

Bai, C., \& Sarkis, J. (2018a). Integrating and extending data and decision tools for Sustainable thirdparty reverse logistics provider selection. Computers \& Operations Research, 1-20. https://doi.org/10.1016/j.cor.2018.06.005

Bai, C., \& Sarkis, J. (2018b). Evaluating complex decision and predictive environments: the case of green supply chain flexibility. Technological and Economic Development of Economy, 24(4), 1630-1658. https://doi.org/10.3846/20294913.2018.1483977

Chai, J., Liu, J. N., \& Ngai, E. W. (2013). Application of decision-making techniques in supplier selection: a systematic review of literature. Expert Systems with Applications, 40(10), 3872-3885. https://doi.org/10.1016/j.eswa.2012.12.040

Chan, F. T. S. (2003). Performance measurement in a supply chain. International Journal of Advanced Manufacturing Technology, 21(7), 534-548. https://doi.org/10.1007/s001700300063

Chatterjee, K., \& Samarjit, K. A. R. (2018). Supplier selection in Telecom supply chain management: a Fuzzy-Rasch based COPRAS-G method. Technological and Economic Development of Economy, 24(2), 765-791. https://doi.org/10.3846/20294913.2017.1295289

Deng, J. L. (1989). Introduction to grey system theory. The Journal of Grey System, 1(1), 1-24.

Fallahpour, A., Olugu, E. U., Musa, S. N., Wong, K. Y., \& Noori, S. (2017). A decision support model for sustainable supplier selection in sustainable supply chain management. Computers \& Industrial Engineering, 105, 391-410. https://doi.org/10.1016/j.cie.2017.01.005

Fallahpour, A., Amindoust, A., Antuchevičienè, J., \& Yazdani, M. (2017). Nonlinear genetic-based model for supplier selection: a comparative study. Technological and Economic Development of Economy, 23(1), 178-195. https://doi.org/10.3846/20294913.2016.1189461

Gauthier, C. (2005). Measuring corporate social and environmental performance: the extended lifecycle assessment. Journal of Business Ethics, 59(1), 199-206.

https://doi.org/10.1007/s10551-005-3416-x

Genovese, A., Lenny Koh, S., Bruno, G., \& Esposito, E. (2013). Greener supplier selection: state of the art and some empirical evidence. International Journal of Production Research, 51(10), 2868-2886. https://doi.org/10.1080/00207543.2012.748224

Ho, W., Xu, X., \& Dey, P. K. (2010). Multi-criteria decision making approaches for supplier evaluation and selection: a literature review. European Journal of Operational Research, 202(1), 16-24. https://doi.org/10.1016/j.ejor.2009.05.009

Junior, F. R. L., Osiro, L., \& Carpinetti, L. C. R. (2014). A comparison between Fuzzy AHP and Fuzzy TOPSIS methods to supplier selection. Applied Soft Computing, 21, 194-209.

https://doi.org/10.1016/j.asoc.2014.03.014

Kannan, D., Govindan, K., \& Rajendran, S. (2015). Fuzzy Axiomatic Design approach based green supplier selection: a case study from Singapore. Journal of Cleaner Production, 96, 194-208. https://doi.org/10.1016/j.jclepro.2013.12.076

Kumar, A., Jain, V., \& Kumar, S. (2014a). A comprehensive environment friendly approach for supplier selection. Omega, 42(1), 109-123. https://doi.org/10.1016/j.omega.2013.04.003

Kumar, D. T., Palaniappan, M., Kannan, D., \& Shankar, K. M. (2014b). Analyzing the CSR issues behind the supplier selection process using ISM approach. Resources, Conservation and Recycling, 92, 268278. https://doi.org/10.1016/j.resconrec.2014.02.005

Labuschagne, C., Brent, A. C., \& Claasen, S. J. (2005). Environmental and social impact considerations for sustainable project life cycle management in the process industry. Corporate Social Responsibility and Environmental Management, 12(1), 38-54. https://doi.org/10.1002/csr.76 
Luthra, S., Govindan, K., Kannan, D., Mangla, S. K., \& Garg, C. P. (2017). An integrated framework for sustainable supplier selection and evaluation in supply chains. Journal of Cleaner Production, 140, 1686-1698. https://doi.org/10.1016/j.jclepro.2016.09.078

Mahdiloo, M., Saen, R. F., \& Lee, K. H. (2015). Technical, environmental and eco-efficiency measurement for supplier selection: an extension and application of data envelopment analysis. International Journal of Production Economics, 168, 279-289. https://doi.org/10.1016/j.ijpe.2015.07.010

Mani, V., Gunasekaran, A., \& Delgado, C. (2018). Enhancing supply chain performance through supplier social sustainability: an emerging economy perspective. International Journal of Production Economics, 195, 259-272. https://doi.org/10.1016/j.ijpe.2017.10.025

Rezaei, J., Nispeling, T., Sarkis, J., \& Tavasszy, L. (2016). A supplier selection life cycle approach integrating traditional and environmental criteria using the best worst method. Journal of Cleaner Production, 135, 577-588. https://doi.org/10.1016/j.jclepro.2016.06.125

Sarkis, J., \& Talluri, S. (2002). A model for strategic supplier selection. Journal of Supply Chain Management, 38(1), 18-28. https://doi.org/10.1111/j.1745-493X.2002.tb00117.x

Sarkis, J., \& Dhavale, D. G. (2015). Supplier selection for sustainable operations: a triple-bottom-line approach using a Bayesian framework. International Journal of Production Economics, 166, 177-191. https://doi.org/10.1016/j.ijpe.2014.11.007

Shahryari Nia, A., Olfat, L., Esmaeili, A., Rostamzadeh, R., \& Antuchevičienè, J. (2016). Using fuzzy Choquet Integral operator for supplier selection with environmental considerations. Journal of Business Economics and Management, 17(4), 503-526. https://doi.org/10.3846/16111699.2016.1194315

Wilhelm, M. M., Blome, C., Bhakoo, V., \& Paulraj, A. (2016). Sustainability in multi-tier supply chains: understanding the double agency role of the first-tier supplier. Journal of Operations Management, 41, 42-60. https://doi.org/10.1016/j.jom.2015.11.001 